Brazilian Journal

of Chemical

Engineering

\title{
PRODUCTION AND CHARACTERIZATION OF PRECIPITATED SILICA FROM PALM OIL MILL FLY ASH USING $\mathrm{CO}_{2}$ IMPREGNATION AND MECHANICAL FRAGMENTATION
}

\author{
Panca S. Utama ${ }^{1}$, Ram Yamsaengsung ${ }^{2 *}$ and Chayanoot Sangwichien ${ }^{2}$ \\ ${ }^{1}$ Universitas Riau, Faculty of Engineering, Chemical Engineering Department, Pekanbaru, Indonesia. ORCID: 0000-0002-6829-1321 \\ ${ }^{2}$ Prince of Songkla University, Faculty of Engineering, Chemical Engineering Department, Hatyai, Thailand. \\ E-mail: ram.y@psu.ac.th, ORCID: 0000-0001-8380-7560
}

(Submitted: August 26, 2017 ; Revised: December 15, 2017 ; Accepted: January 30, 2018)

\begin{abstract}
In this research, sol-gel precipitation using $\mathrm{CO}_{2}$ impregnation and mechanical fragmentation method was applied to produce precipitated silica from Palm Oil Mill Fly Ash (POMFA). Carbon dioxide $\left(\mathrm{CO}_{2}\right)$ was used in order to reduce the cost of the process and to enable sodium hydroxide recovery. The precipitation process was done in a stirred temperature-controlled baffled glass precipitator. The response surface method with the central composite design was applied to optimize the stirring speed and the $\mathrm{CO}_{2}$ flow rate. The $\mathrm{pH}$ and the temperature of the precipitation process were varied for tailoring the specific surface area of the precipitated silica. The mechanical fragmentation and wet crushing process were applied to control the agglomerate particle size of the precipitated silica obtained. The results show that precipitated silica with a specific surface area in the range of $50-140 \mathrm{~m}^{2} / \mathrm{g}$ can be obtained.

Keywords: Carbon dioxide; Mechanical fragmentation; Palm oil mill fly ash; Precipitated silica; Sol-gel precipitation.
\end{abstract}

\section{INTRODUCTION}

The market of synthetic amorphous silica, including silica sol, silica gel, precipitated silica and fume silica, has grown rapidly. In 2015 , about $70 \%$ of the synthetic amorphous silica demand was for precipitated silica. Precipitated silica is widely used in many industries, with the largest volume being used in rubber and plastic industries as reinforced filler. It is predicted that, in 2018, the valuation of the global precipitated silica market will be $\$ 7$ billion USD (Future Market Insights, 2015). To produce high quality amorphous silica, the alkaline extraction method for silica production from silica-containing agricultural waste is generally used. Raw materials such as rice husk ash (Kamath and Proctor, 1998; Kalapathy et al., 2000; Krishnamoorthy et al., 2015), oat husk ash (Zenukhova et al., 2006), sugar cane bagasse ash (Affandi et al., 2009; Amin at al., 2016) and corn cob ash (Shim et al., 2015) have been used to produce amorphous silica.

Recently, there have been a number of developments of amorphous silica products from biological sources into value-added products. For example, amorphous silica derived from Panicum milianare husks ash was modified using a magnesiothermic process to produce uniform mesoporous silicon (Srinivasan et al., 2015). Likewise, surface silica aerogel from fly ash acid sludge was modified using trimethylchlorosilane (TMCS) via solvent exchange and surface modification to obtain a higher specific surface area (SSA) product with lower density and larger pore volume (Cheng et al., 2016). In addition, wet silica aerogel micro-particles obtained from rice husk ash were modified using a sol-gel process in water-in-oil emulsion and dried

\footnotetext{
* Corresponding author: Ram Yamsaengsung - E-mail: ram.y@psu.ac.th
} 
via supercritical $\mathrm{CO}_{2}$ to produce products for a drug delivery process (Rajanna et al., 2015).

One of the potential agricultural silica-containing wastes in Southeast Asia is Palm Oil Mill Fly Ash (POMFA). Palm oil production in South East Asia in 2014 was 54,800 million tons (Indexmundi, 2016). The solid waste consists of fiber, shell and empty fruit bunches. Around 85\% fiber and 15\% shell were used as fuel for boiler with $5 \%$ of the fuel being left unburned and generating ash (Tay and Show, 1995). Thus, it can be estimated that the ash production in 2014 was 3.014 billion tons. In the authors' previous work, alkaline extraction and mechanical fragmentation in sol-gel precipitation using sulfuric acid were applied to produce precipitated silica from POMFA. The extraction kinetics and the effect of the mechanical fragmentation time on the particle size were studied (Utama et al., 2016). However, the use of sulfuric acid in sol-gel precipitation made the process need a large amount of chemicals, which made the process expensive (Rozainee et al., 2008). In this work, carbon dioxide $\left(\mathrm{CO}_{2}\right)$ was used to destabilize the silica extract in order to enable sodium hydroxide recovery, which can reduce the amount of chemicals needed for the process. The use of $\mathrm{CO}_{2}$ in the sol-gel precipitation process produces sodium carbonate in the filtrate of the precipitation process. The sodium carbonate can be converted to sodium hydroxide using calcium hydroxide (Subukhrisna et al. 2007). The reaction of the precipitation process and the sodium hydroxide recovery can be written as follows:

$$
\begin{aligned}
& \mathrm{Na}_{2} \mathrm{O} \cdot \mathrm{xSiO}_{2}(\mathrm{l})+\mathrm{CO}_{2}(\mathrm{~g}) \rightarrow \mathrm{xSiO}_{2}(\mathrm{~s})+\mathrm{Na}_{2} \mathrm{CO}_{3}(1) \\
& \mathrm{Na}_{2} \mathrm{CO}_{3}(\mathrm{l})+\mathrm{Ca}(\mathrm{OH})_{2}(\mathrm{~s}) \rightarrow \mathrm{CaCO}_{3}(\mathrm{~s})+2 \mathrm{NaOH}(1)
\end{aligned}
$$

Furthermore, the particle size distribution (PSD) of the precipitated silica agglomerate obtained in the previous work was bimodal. In this work, after the filtration process, the precipitated silica cake was blended with distilled water in a household blender in order to obtain a more uniform particle size and to wash the precipitated silica simultaneously. In summary, the contributions of this work are described as follows:

a. The process enables the tailoring of the specific surface area of the precipitated silica.

b. The process enables the recovery of the sodium hydroxide used in the extraction process.

c. The process can produce a uni-modal precipitated silica particle size distribution.

d. The process can produce mesopore precipitated silica which comes in compacted uniform spheres of fairly regular array.

\section{MATERIALS AND METHODS}

\section{Materials}

The POMFA, having the composition of $30.44 \%$ carbon and 39.02\% silica from Sawee Industrial Palm Oil Ltd., Chumporn, Thailand, was extracted using 1.4 $\mathrm{N}$ sodium hydroxide at the temperature of $105^{\circ} \mathrm{C}$ for $60 \mathrm{~min}$. The mass of POMFA to $\mathrm{NaOH}$ volume ratio of $0.2341 \mathrm{~g} / \mathrm{cm}^{3}$ and the stirring speed of 1065 RPM were used in the extraction process. The silica extract has a silica content of $5.5 \%(\mathrm{~m} / \mathrm{v})$, while the silica to $\mathrm{Na}_{2} \mathrm{O}$ mol ratio was 1.1 (Utama et al, 2016). The industrial grade carbon dioxide of $99.5 \%$ purity was used as the precipitating agent.

\section{Methods}

The precipitation was done in a temperaturecontrolled baffled glass precipitator $(\mathrm{H}=\mathrm{D}=100 \mathrm{~mm})$ and strirred by a $5 \mathrm{~cm}$ four-blade 45 degree pitch turbine type stirrer. The $\mathrm{CO}_{2}$ was fed into the precipitator by a nozzle. The precipitator was filled with $600 \mathrm{~cm}^{3}$ of the silica extract. The $\mathrm{CO}_{2}$ flow rate $\left(\right.$ low $=150 \mathrm{~cm}^{3} / \mathrm{min}$; high $=450 \mathrm{~cm}^{3} / \mathrm{min}$ ) and the stirring speed (low $=500$ RPM; high = 1000 RPM) were varied. The operating conditions above were chosen because, in that range, visually the $\mathrm{CO}_{2}$ bubbles were well dispersed in the silica extract. The response surface method (RSM) with central composite design (CCD) was applied to optimize the process. The time required until the gel formed was used to calculate the volume of $\mathrm{CO}_{2}$ needed for the precipitation process. After the gel formed, the flow of $\mathrm{CO}_{2}$ was stopped and the stirring speed was increased to 1160 RPM. The methodology and operating conditions used for sol-gel precipitation and the mechanical fragmentation process were adapted from the literature (Cai et al. 2009; Quarch et al., 2010; Utama et al., 2016). At the temperature of $30^{\circ} \mathrm{C}$, the $\mathrm{pH}$ was varied from 9.5 to 8.0 . At the optimum $\mathrm{pH}$, the temperature was varied from 30 to $90^{\circ} \mathrm{C}$. At the temperature of $30^{\circ} \mathrm{C}$, the $\mathrm{pH}$ of 9.5 and the mechanical fragmentation time of $100 \mathrm{~min}$, the particle size distribution (PSD) of the precipitated silica was analysed using the Laser Diffraction Particle Size Analyzer (LPSA), Coulter LS320. The precipitated silica and the liquor were separated using a vacuum filter (EYELA A-3S). The cake was mixed with 1000 $\mathrm{cm}^{3}$ of distilled water and crushed using a $2000 \mathrm{~cm}^{3}$ household blender (AJ BL001). At 5 min interval, 15 $\mathrm{cm}^{3}$ of sample was taken out and the particle size was measured using the LPSA. Next, the precipitated silica was separated from the solution using a vacuum filter before being washed and dried. The spesific surface area (SSA) of the precipitated silica were obtained by the Brunauer-Emmett-Teller (BET) method using a surface area analyzer (Quantachrome Nova 2000 e, USA). The physical morphology of the precipitated 
silica was determined by a scanning electron microscope (JEOL JSM-5800LV, Japan). The FTIR (Vertex 70, Bruker, USA) was used to identify the chemical bonds in the product. The elemental analysis of the precipitated silica product was conducted by the energy-dispersive X-ray (EDX) method using an SEM EDX (JEOL JSM-5800LV, Japan) and XRF (PW 2400 Philips, Netherland). The X-Ray diffraction (XRD) measurements were carried out with an X-ray Diffractometer (Philips X'Pert MPD, Philips, Netherland) to confirm that the product was in the amorphous form.

\section{Statistical analysis}

The RSM-CCD with the full factorial design of 4 cube points, 4 axial points and 5 center points in cube was used to optimize the process. The second order polynomial equation was used to fit the experimental data. The model for the response $(\eta)$ was:

$$
\eta=\beta_{0}+\beta_{1} x_{1}+\beta_{2} x_{2}+\beta_{11} x_{1}^{2}+\beta_{22} x_{2}^{2}+\beta_{12} x_{1} x_{2}+\varepsilon
$$

where $\eta$ : $\mathrm{CO}_{2}$ used $\left(\mathrm{cm}^{3}\right), \beta_{0}$ (constant term), $\beta_{1}$ and $\beta_{2}$ (linear effects), $\beta_{11}$ and $\beta_{22}$ (quadratic effects), $\beta_{12}$ and $\beta_{13}$ (interaction effects), $x_{1}$ : stirring speed (RPM), $\mathrm{x}_{2}: \mathrm{CO}_{2}$ flow rate $\left(\mathrm{cm}^{3} / \mathrm{min}\right)$ and $\varepsilon$ : random error. The regression analysis, ANOVA and optimization process were done using Minitab 16.1.1. ANOVA was used to test the compatibility of the model with the experimental data. The Lack of Fit (LoF) test was used to investigate the adequacy of the model (Montgomery, 2001). The optimum condition was verified by conducting experiments at that condition. Responses were monitored and results were compared with model predictions (Ramos-de-la-Pena et al., 2012).

\section{RESULTS AND DISCUSSION}

The effect of the $\mathrm{CO}_{2}$ flow rate and the stirring speed on the volume of $\mathrm{CO}_{2}$ required for the precipitation process is shown in Table 1. From the results, it can be seen that increasing the $\mathrm{CO}_{2}$ flow rate and the stirring speed reduces the time required to reach the gel point. It is most likely that the rate-determining step of the $\mathrm{CO}_{2}$ absorption into the sodium silicate solution in the stirred precipitator is the mass transfer processes from gas to bulk liquid. On the other hand, increasing the stirring speed enhanced the breaking up of the bubbles and makes the size of the bubbles smaller. The smaller bubbles increase the gas-liquid contact area and make the rate of mass transfer increase. This result aligns with the findings of Sardeing et al. (2004), which suggested that the rate of the $\mathrm{CO}_{2}$ absorption increases with increasing $\mathrm{CO}_{2}$ flow rate because of larger gas hold up and the gas-liquid contact surface area.
Table 1. Extraction variables and experimental data.

\begin{tabular}{|c|c|c|c|c|c|}
\hline \multirow[b]{2}{*}{$\begin{array}{l}\text { Run } \\
\text { No. }{ }^{a}\end{array}$} & \multicolumn{3}{|c|}{ Variables } & \multirow[b]{2}{*}{$\begin{array}{c}\text { Time } \\
\text { Required } \\
\text { (min) }\end{array}$} & \multirow[b]{2}{*}{ 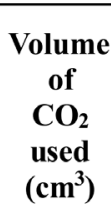 } \\
\hline & $\begin{array}{c}\text { Pt } \\
\text { Type }\end{array}$ & $\begin{array}{c}\text { Stirring } \\
\text { Speed } \\
\text { (RPM) } \\
x_{1}\end{array}$ & $\begin{array}{c}\mathrm{CO}_{2} \\
\text { Flow } \\
\text { rate } \\
\left(\mathrm{cm}^{3} / \mathrm{min}\right) \\
x_{2}\end{array}$ & & \\
\hline 1 & 0 & 750 & 300 & 28.87 & 8662 \\
\hline 2 & 0 & 750 & 300 & 28.41 & 8524 \\
\hline 3 & 1 & 1000 & 450 & 14.76 & 6641 \\
\hline 4 & 0 & 750 & 300 & 28.31 & 8492 \\
\hline 5 & 1 & 500 & 150 & 65.00 & 9750 \\
\hline 6 & -1 & 396 & 300 & 52.97 & 15892 \\
\hline 7 & 1 & 500 & 450 & 34.99 & 15746 \\
\hline 8 & -1 & 1104 & 300 & 22.07 & 6621 \\
\hline 9 & 0 & 750 & 300 & 28.60 & 8580 \\
\hline 10 & 0 & 750 & 300 & 28.70 & 8611 \\
\hline 11 & 1 & 1000 & 150 & 38.80 & 5820 \\
\hline 12 & -1 & 750 & 512 & 19.41 & 9940 \\
\hline 13 & -1 & 750 & 88 & 60.01 & 5273 \\
\hline
\end{tabular}

${ }^{\text {a }}$ Treatments are run in random order.

The regression coefficient and the analysis of variance, which can be used to determine the significance of each regression coefficient and the variables, are shown in Table 2.

It can be seen that all the variables and the regression coefficients gave significant effects on the response variable. The lack of fit test gave a p-value of 0.495 ( $p>0.05$ ). So there is no evidence that the model proposed does not adequately explain the variation of the response. From the optimization process using the Minitab 16.1.1 software, the optimum condition for destabilizing the silica extract was at a stirring speed of $882 \mathrm{RPM}$ and a $\mathrm{CO}_{2}$ flow rate of $88 \mathrm{~cm}^{3} / \mathrm{min}$. The predictive result of the $\mathrm{CO}_{2}$ required to reach the gel point ( $\mathrm{pH}$ 9.5) was $4882 \mathrm{~cm}^{3}$, which fell within the range of the laboratory experimental validation which was $4886 \pm 56 \mathrm{~cm}^{3}$.

The application of the mechanical fragmentation process for breaking up the gel and controlling the size of the agglomerate resulted in precipitated silica with

Table 2. Significance of regression coefficients for silica conversion (\%) and ANOVA.

\begin{tabular}{lccc}
\hline \multicolumn{1}{c}{ Source } & $\begin{array}{r}\text { Variable } \\
\text { constant }\end{array}$ & $\begin{array}{r}\text { Regression } \\
\text { Coefficient }\end{array}$ & p values \\
\hline Regression & & & $0.000^{\mathrm{a}}$ \\
Linear & $\beta_{0}$ & 17587.7 & $0.000^{\mathrm{a}}$ \\
& $\beta_{1}$ & -35.2627 & $0.000^{\mathrm{a}}$ \\
$x_{1}$ & $\beta_{2}$ & 49.5651 & $0.000^{\mathrm{a}}$ \\
$x_{2}$ & & & $0.000^{\mathrm{a}}$ \\
Square & $\beta_{11}$ & 0.02169 & $0.000^{\mathrm{a}}$ \\
$x_{1}{ }^{2}$ & $\beta_{22}$ & -0.02085 & $0.000^{\mathrm{a}}$ \\
$x_{2}{ }^{2}$ & & & $0.000^{\mathrm{a}}$ \\
Interaction & $\beta_{12}$ & -0.03450 & $0.000^{\mathrm{a}}$ \\
$x_{1 . X}$ & & & \\
Residual error & & & 0.495 \\
Lack of Fit & & & \\
\hline R-Sq $=99.18 \% \mathrm{R}-\mathrm{Sq}(\mathrm{pred})$ & $=96.74 \% \mathrm{R}-\mathrm{Sq}(\mathrm{adj})=98.60 \%$. & \\
${ }^{\mathrm{a}}$ significance at $\alpha=0.05$. & & &
\end{tabular}


a mean volume weighed diameter $\left(\mathrm{d}_{50}\right)$ of $116.25 \pm 4.41$ $\mu$ m using a stirring speed of $1160 \mathrm{RPM}$ for $100 \mathrm{~min}$. This result is in accordance with the $\mathrm{d}_{50}$ from the previous work, which was $114.7 \mu \mathrm{m}$ at the same stirring speed and time, and the work of Quarch et al. (2010) under a similar condition which was $100 \mu \mathrm{m}$. According to Schlomach and Kind (2004), the destruction of the gel by mechanical force was followed by re-arrangement and compaction of agglomerates, resulting in a final diameter of silica fragments in the range of $30-130$ $\mu \mathrm{m}$. The PSD of the precipitated silica obtained was bimodal. The plot of the $d_{50}$ of the precipitated silica versus time and the comparison of the PSD before and after crushing are depicted in Figures 1 and 2, respectively.

Figure 1 shows the comparison of the PSD of the precipitated silica obtained from mechanical fragmentation and compaction before and after crushing. The crushing process using a household blender for 25 min effectively reduced the agglomerate

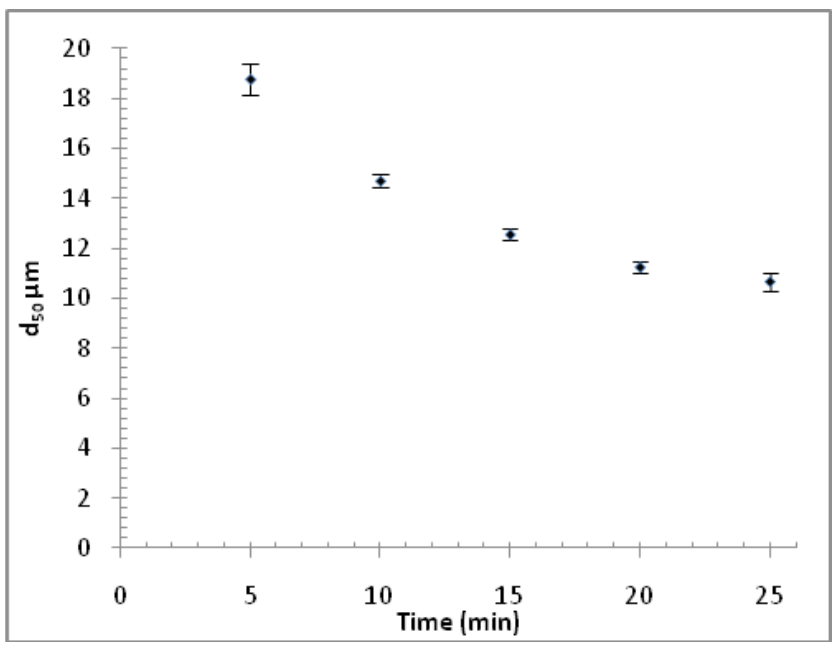

Figure 1. The plot of $\mathrm{d}_{50}$ of the precipitated silica versus time.

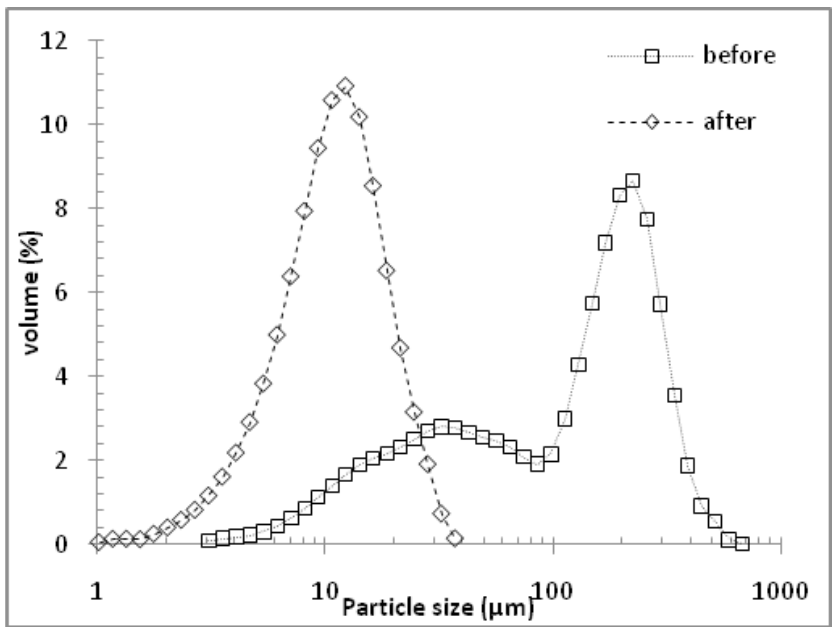

Figure 2. The comparison of the precipitated silica PSD before and after crushing. of precipitated silica into $10.67 \pm 1.44 \mu \mathrm{m}$ size and made the PSD uni-modal. Figure 2 shows that a crushing time of 5 min can reduce the $d_{50}$ to $18.77 \pm 2.57 \mu \mathrm{m}$, while continued crushing for more than 15 min resulted in less drastic reduction of $\mathrm{d}_{50}$ into even smaller sizes.

The effect of the $\mathrm{pH}$ and the temperature on the specific surface area (SSA) of the precipitated silica obtained are depicted in Figures 3 and 4, respectively.

From Figure 3, decreasing the $\mathrm{pH}$ from 8.75 to 8.30 significantly decreased the SSA of the precipitated silica obtained from $140.75 \mathrm{~m}^{2} / \mathrm{g}$ to $79.91 \mathrm{~m}^{2} / \mathrm{g}$. The SSA was closely related to the primary particle size; the smaller the primary particle size, the larger the specific surface area of the precipitated silica obtained. According to Baldyga et al. (2012), the $\mathrm{pH}$ of the precipitation process has a significant effect on the aggregation rate. Increasing the $\mathrm{pH}$ to a certain range decreases the aggregation rate, so that the resulting particle size becomes smaller.

In Figure 4, increasing the temperature decreases the SSA of the precipitated silica. This result is

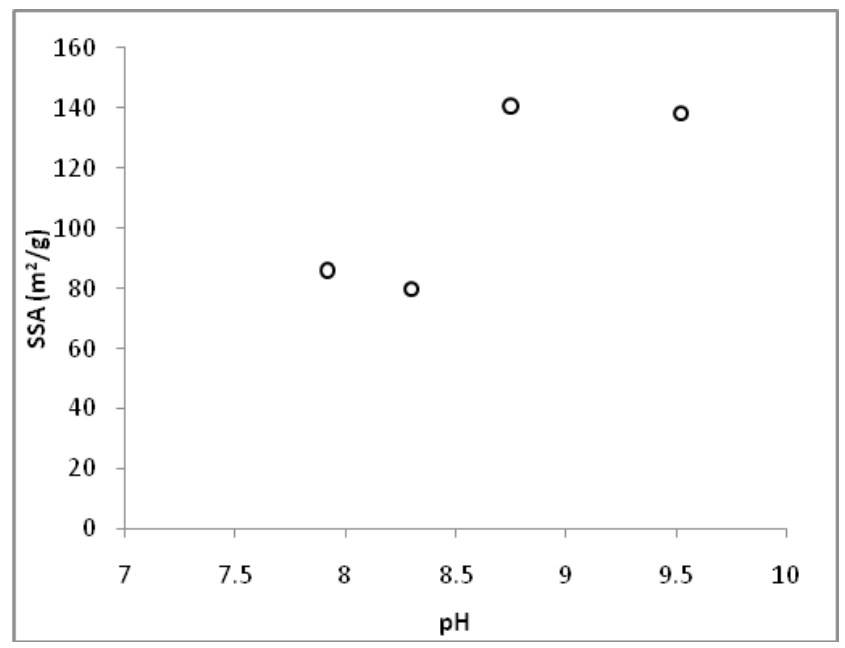

Figure 3. The effect of the $\mathrm{pH}$ on the SSA of the precipitated silica at temperature of $30^{\circ} \mathrm{C}$.

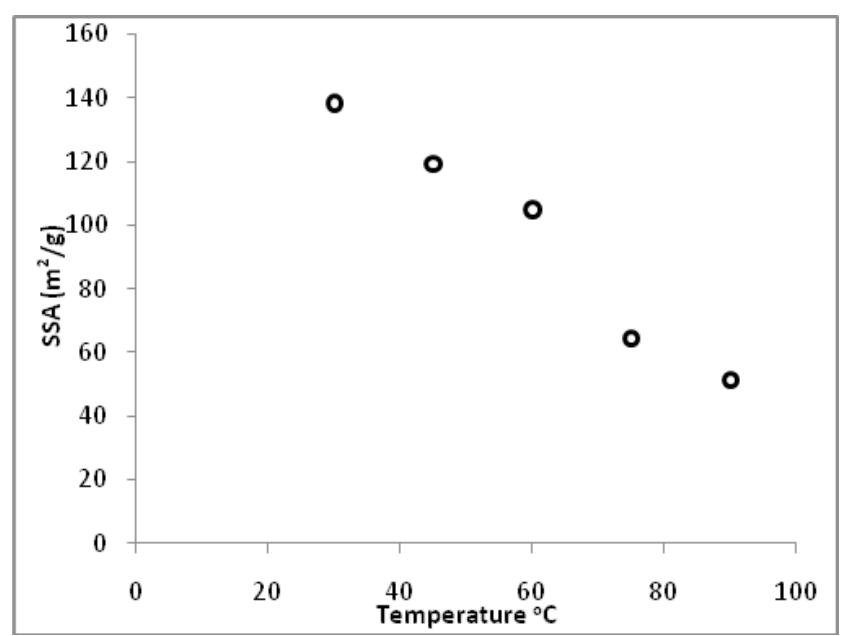

Figure 4. The effect of the temperature on the SSA of the precipitated silica at $\mathrm{pH}$ of 9.5 . 
consistent with Cai et al. (2009) who suggested that higher temperatures increase the nuclei growth with the resulting particle size becoming larger and the SSA of the precipitated silica becoming smaller. The SSA of the precipitated silica obtained was in the range of $50-140 \mathrm{~m}^{2} / \mathrm{g}$, which is suitable for reinforcing rubber filler product, such as shoe soles and mechanical rubber goods. Finally, the precipitated silica obtained at the temperature of $30^{\circ} \mathrm{C}$ and $\mathrm{pH}$ of 9.5 was characterized to investigate the physical and the chemical properties.

Figure 5 depicts the micrograph of the precipitated silica using the SEM at magnification of 30,000 times. It is shown that the form of and the size of the primary particle are quite uniform. The primary particle size measured from the SEM image using software Image J $1.49 \mathrm{v}$ was $58.96 \pm 5.40 \mathrm{~nm}$. This result is in accordance with the average primary particle size of the amorphous silica obtained from corn cob ash reported by Shim et al. (2015), which was $60 \mathrm{~nm}$. The SSA of the typical precipitated silica obtained in the conditions mentioned above was $138 \mathrm{~m}^{2} / \mathrm{g}$.

Figure 6 illustrates the isotherm of nitrogen adsorption-desorption of the typical precipitated silica obtained. The characteristic of the nitrogen adsorption isotherm and the hysteresis loop is in accordance with a type IV isotherm and the hysteresis loop of type $\mathrm{H} 1$ of the IUPAC classification. This can be associated with mesopore materials which are approximately uniform spheres in a fairly regular array (Sing et al., 1985).

The FTIR spectrum of the typical precipitated silica obtained is presented in Figure 7 showing five main IR bands in the spectrum. The $471 \mathrm{~cm}^{-1}$ and the $800 \mathrm{~cm}^{-1} \mathrm{IR}$ bands are associated with O-Si-O bending vibrations and the Si-O-Si symmetric stretching vibrations, respectively. The sharp and strong IR band

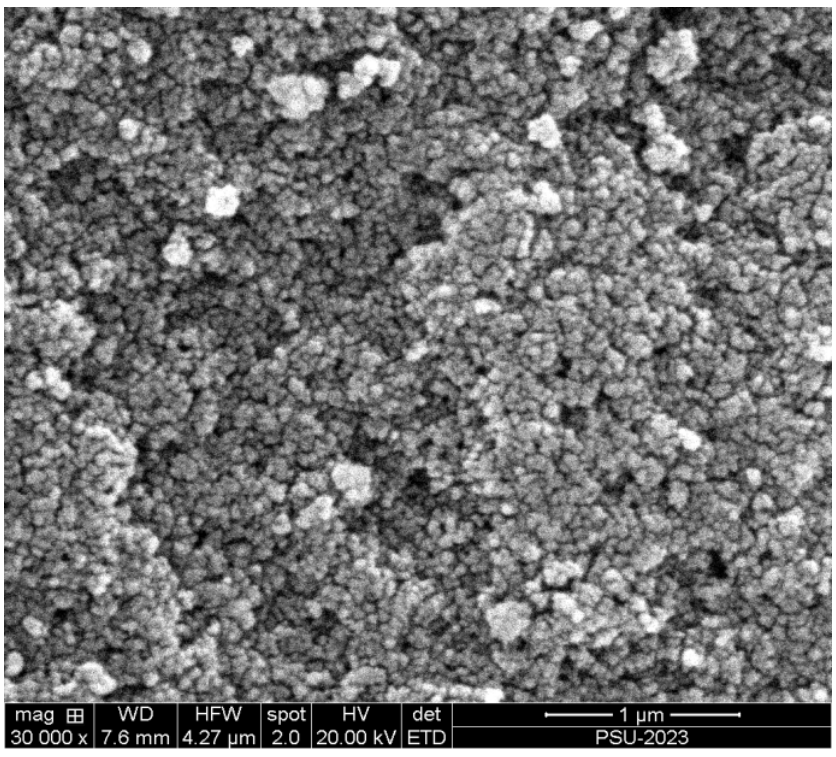

Figure 5. The SEM of the precipitated silica.

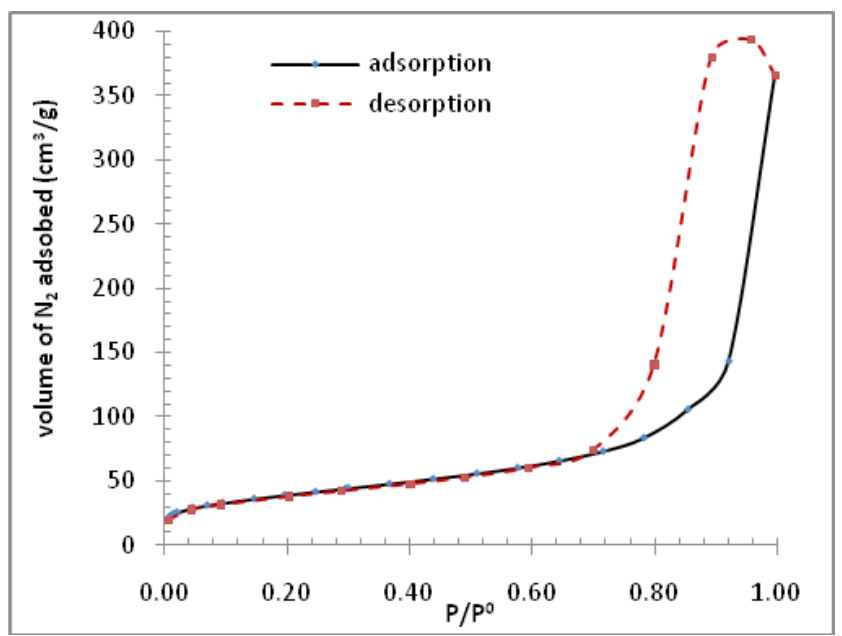

Figure 6. The isotherm of nitrogen adsorptiondesorption.

at $1107 \mathrm{~cm}^{-1}$ is due to the $\mathrm{Si}-\mathrm{O}-\mathrm{Si}$ asymmetric stretching vibration. The $1641 \mathrm{~cm}^{-1}$ and the $3452 \mathrm{~cm}^{-1}$ IR bands are due to bending vibrations and stretching vibrations of the water molecule, respectively. The FTIR spectrum of the precipitated silica obtained agrees well with the FTIR spectrum of amorphous silica produced from commercial sodium silicate precipitates using sulfuric acid (Music et al., 2011) and amorphous silica powder obtained by the carbonation method (Cai et al., 2009).

Furthermore, Figure 8 presents the XRD pattern of the precipitated silica obtained. There is no sharp peak, indicating that there is no crystalline material in the precipitated silica. The XRD pattern of the amorphous material has the characteristic of having a broad hump between 15 to $35^{\circ}$ of the Bragg angle $2 \theta$ (Kamath and Proctor, 1998). The peak of the broad hump recorded in the XRD pattern is the same as the amorphous silica obtained by sol-gel procedure reported by Martinez et al. (2006), which has an amorphous peak at Bragg angle $2 \theta=23$ degrees.

The SEM-EDS spectrum in Figure 9 shows the impurities of the precipitated silica obtained. There are

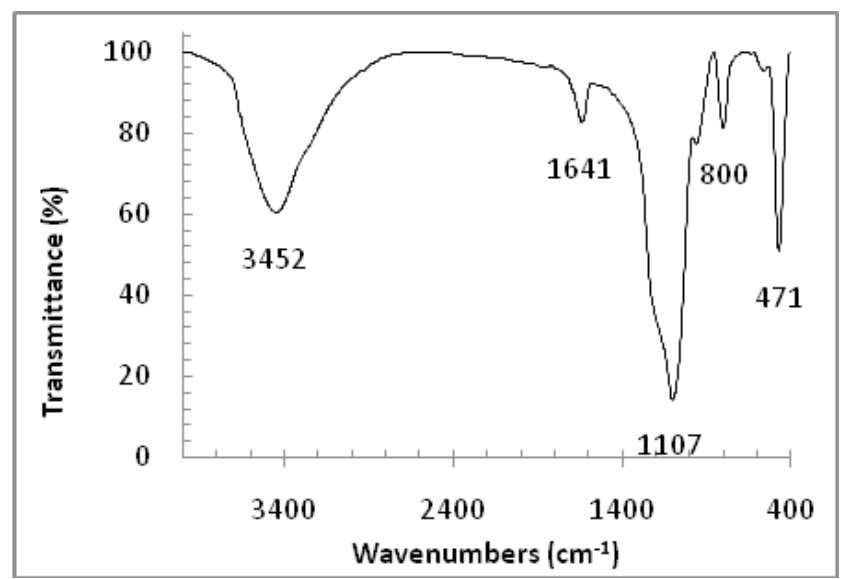

Figure 7. FTIR spectrum of the precipitated silica obtained. 


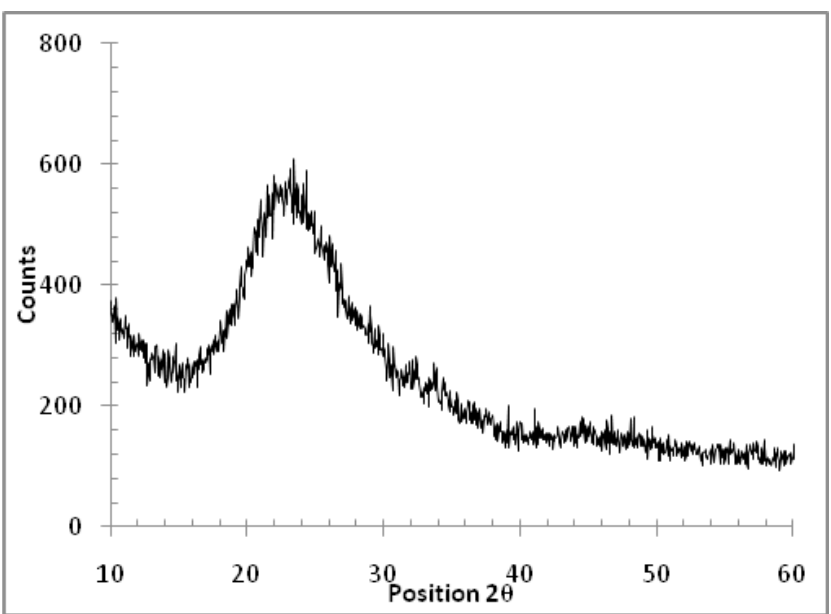

Figure 8. XRD pattern of the precipitated silica.

four elements of impurities found in the precipitated silica: $\mathrm{C}, \mathrm{K}, \mathrm{Al}$ and $\mathrm{Na}$. The elements $\mathrm{K}$ and $\mathrm{Al}$ were found in the POMFA. The $\mathrm{C}$ element was found in the carbonate form in the POMFA and in the precipitation process when $\mathrm{CO}_{2}$ is dissolved in the silica extract to form the carbonate compound. There was a small amount of these elements carried over into the precipitated silica.

The results of semi-quantitative XRF analysis confirm the elements that were identified in the SEM-EDS spectra. The chemical composition of the precipitated silica analyzed using XRF is shown in Table 3.

It can be seen that the $\mathrm{C}$ element was not identified. In XRF analysis, the precipitated silica was heated in a furnace up to $1000{ }^{\circ} \mathrm{C}$ before analysis and made the carbonate decompose to carbon dioxide. The purity
Table 3. Chemical composition of the precipitated silica product.

\begin{tabular}{cccc}
\hline No & Oxide & $\begin{array}{c}\text { Weight } \\
\text { a }\end{array}$ & $\begin{array}{c}\text { Standard } \\
\text { (Roemp, 2001) }\end{array}$ \\
\hline 1 & $\mathrm{SiO}_{2}$ & $96.90 \pm 0.21$ & $\geq 95$ \\
2 & $\mathrm{Na}_{2} \mathrm{O}$ & $1.59 \pm 0.10$ & $0.2-2.4$ \\
4 & $\mathrm{Al}_{2} \mathrm{O}_{3}$ & $0.46 \pm 0.06$ & - \\
5 & $\mathrm{~K}_{2} \mathrm{O}$ & $1.29 \pm 0.14$ & - \\
7 & $\mathrm{LOI}$ & $7.12 \pm 1.85$ & $2-15$ \\
\hline
\end{tabular}

${ }^{\mathrm{a}}$ mean of triplicate determination

of the precipitated silica obtained of $96.90 \pm 0.21 \%$ is in the range of standard commercial precipitated silica. The purity of precipitated silica obtained in this process is slightly higher and the impurities are fewer compare to the precipitated silica obtained by sulfuric acid sol-gel precipitation. The purity of precipitated silica obtained by sulfuric acid sol-gel precipitation was $94.92 \pm 0.12 \%$ and the impurities were: $\mathrm{K}, \mathrm{Al}, \mathrm{Na}$, Fe and S (Utama et al., 2016). The higher purity and fewer impurities might be because, in this process, the precipitated silica was wet crushed using a blender and the particle size reduced after the sol-gel precipitation process. The wet crush process released the impurities which were trapped in the agglomerate and made the washing process more effective.

Considering the results, the sol-gel precipitation process using $\mathrm{CO}_{2}$ impregnation and mechanical fragmentation, combined with the alkaline extraction process, shows great promise to be developed to produce precipitated silica from waste of commercial crops, not only POMFA but also sugar cane ash, rice husk ash, corn ash and other siliceous containing ash. This process can be applied to produce precipitated

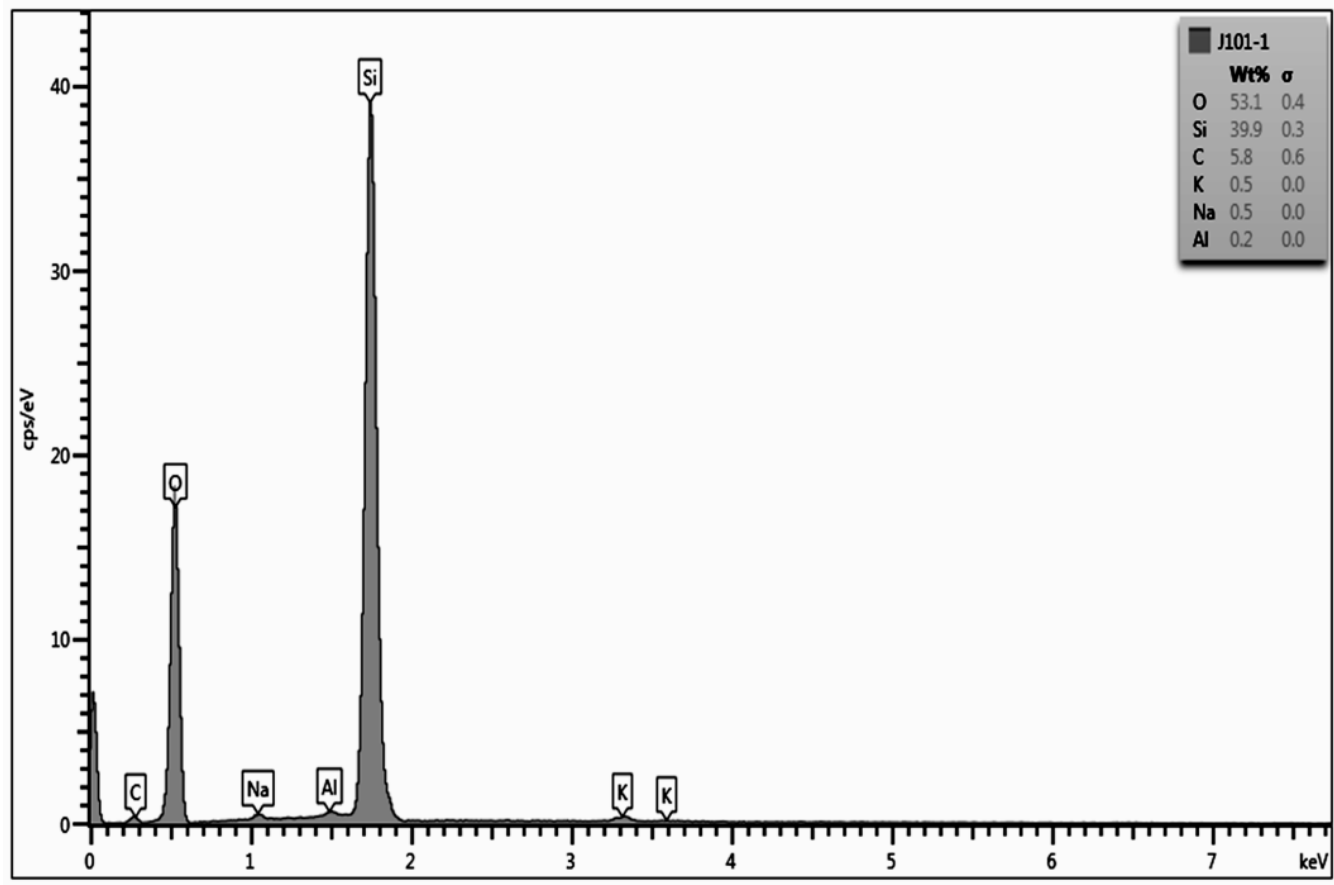

Figure 9. The SEM-EDS spectrum of the precipitated silica. 
silica from silica extract with low silica to sodium oxide ratio and the specific surface area of the product can be tailored by varying the $\mathrm{pH}$ and temperature of the precipitation process. Moreover, with the sodium hydroxide recovery process, the process might be economically viable. In the alkaline extraction combined with sulfuric acid, sol-gel precipitation need large amounts of sodium hydroxide and sulfuric acid made the process hard to compete with the conventional precipitated silica production from silica sand and soda ash. From the previous work and this work, it can be estimated that, from $1 \mathrm{~kg}$ of POMFA, around $200 \mathrm{~g}$ of precipitated silica can be produced and, if it is assumed that $70 \%$ of sodium hydroxide can be recovered, the sodium hydroxide needed is only $83 \mathrm{~g}$. The process will be more competitive if the $\mathrm{CO}_{2}$ source is the flue gas of the combustion process.

\section{CONCLUSIONS}

In this paper, sol-gel precipitation using $\mathrm{CO}_{2}$ impregnation and mechanical fragmentation has successfully been applied to produce precipitated silica from POMFA. The optimum condition for precipitating $600 \mathrm{~cm}^{3}$ of silica extract which has a silica content of $5.5 \%(\mathrm{~m} / \mathrm{v})$ and a mol ratio of silica to $\mathrm{Na}_{2} \mathrm{O}$ of 1.1 was a stirring speed of $882 \mathrm{RPM}$ and $\mathrm{CO}_{2}$ flow rate of 88 $\mathrm{cm}^{3} / \mathrm{min}$. The $\mathrm{CO}_{2}$ needed for the sol-gel precipitation process was $4886 \pm 56 \mathrm{~cm}^{3}$. The $\mathrm{d}_{50}$ of the precipitated silica particle size of $10.67 \pm 1.44 \mu \mathrm{m}$ can be obtained by a wet crushing process using a household blender. The BET specific surface area of the precipitated silica obtained can be tailored by varying the $\mathrm{pH}$ and the temperature of the precipitation process. The SSA of the precipitated silica obtained was in the range of 50 $-140 \mathrm{~m}^{2} / \mathrm{g}$. The characteristics of typical precipitated silica obtained, which were analyzed using FTIR, SEM, SEM-EDS and XRD, match the characteristics of the silica from other references obtained at the laboratory level.

\section{ACKNOWLEDGEMENTS}

This work was financially supported by the Graduate School of the Prince of Songkla University. The author received a scholarship for his graduate degree from DGHE Indonesia.

\section{REFERENCES}

Affandi, S., Setyawan, H., Winardi, S., Purwanto, A., and Balgis, R., A Facile Method for Production of High-Purity Silica Xerogels from Bagasse Ash, Advanced Powder Technology, 20(5), 468-472 (2009). https://doi.org/10.1016/j.apt.2009.03.008
Amin N.U., Khattak S, Noor S, and Ferroze, I., Synthesis and Characterization of Silica from Bottom Ash of Sugar Industry, J. Clean Prod., 117, 207-211 (2016). https://doi.org/10.1016/j. jclepro.2016.01.042

Baldyga, J., Jasin, M., Jodko, K. and Petelski. P., Precipitation of Amorphous Colloidal Silica from Aqueous Solutions-Aggregation Problem, Chem. Eng. Sci., 77, 207-216 (2012). https://doi. org/10.1016/j.ces.2012.03.046

Cai, X., Hong, R.Y., Wang, L.S., Wang, X.Y., Li, H.Z. and Wei, D.G., Synthesis of Silica Powders by Pressured Carbonation, Chem. Eng. J., 151(13), 380-386 (2009). https://doi.org/10.1016/j. cej.2009.03.060

Cheng, Y., Xia, M., Luo, F., Li, N., Guo, C. and Wei, C., Effect of Surface Modification on Physical Properties of Silica Aerogels Derived from Fly Ash Acid Sludge, Colloid Surface A. , 490, 200-206 (2016). https://doi.org/10.1016/j. colsurfa.2015.11.055

Future Market Insights. http://www. futuremarketinsights.com/articles/precipitatedsilica-market-to-witness-steady-growth-in-bricsowing-to-demand-from-automotive-and-consumerelectronics-market. [27 December 2015].

Indexmundi. http://www.indexmundi.com/ agriculture/?commodity=palm-oil\&graph=production . [January15, 2016].

Kalapathy, U., Proctor, A. and Shultz, J., A Simple Method for Production of Pure Silica from Rice Hull Ash, Bioresour. Technol., 73(3), 257-262 (2000). https://doi.org/10.1016/S0960-8524(99)00127-3

Kamath, S.R. and Proctor, A., Silica Gel from Rice Hull Ash: Preparation and Characterization, Cereal Chem., 74(4), 484-487 (1998). https://doi. org/10.1094/CCHEM.1998.75.4.484

Krishnamoorthy, S., Iyer, N.R. and Murthy, A.R., Carbonization on Combustion and Biodegradation of Agricultural Waste as a Possible Source of Silica, Appl. Biochem. Biotechnol., 175(3), 16221632 (2015). https://doi.org/10.1007/s12010-014$1362-8$

Martinez, J.R., Palomares, S., Ortega-Zarzosa, G., Ruiz, F. and Chumakov, Y., Rietveld Refinement of Amorphous SiO2 Prepared Via Sol-Gel Method, Mater. Lett., 60(29-30), 3526-3529 (2006). https:// doi.org/10.1016/j.matlet.2006.03.044

Montgomery, D.C., Design and Analysis of Experiments (5th edn), John Wiley \& Sons, New York (2001).

Musić, S., Filipović-Vinceković, N. and Sekovanić, L., Precipitation of Amorphous $\mathrm{SiO}_{2}$ Particles and Their Properties, Braz. J. Chem. Eng., 28(1), 89-94 (2011). https://doi.org/10.1590/S010466322011000100011 
Quarch, K., Durand, E., Schilde, C., Kwade, A. and Klind, M., Mechanical Fragmentation of Precipitated Silica Aggregates, Chem. Eng. Res. Des., 88(12), 1639-1647 (2010). https://doi. org/10.1016/j.cherd.2010.01.007

Rajanna, S.K., Kumar, D., Vinjamur, M. and Mukhopadhyay, M., Silica Aerogel Microparticles from Rice Husk Ash for Drug Delivery, Ind. Eng. Chem. Res., 54(3), 946-956 (2015). https://doi. org/10.1021/ie503867p

Ramos-de-la-Pena, A.M., Catherine, M.G.C., Renard, C.M.G.C., Wicker, L., Montañez, J., María de la Luz Reyes-Vega, M.L. and Contreras-Esquivel, J.C., Optimization of the Liquefaction and Saccharification of Structural Polysaccharides of Jicama (Pachyrhizuserosus L.) Tissue by Enzymatic Pulping, LWT-Food Sci. Technol., 46(1), 232-238 (2012). https://doi.org/10.1016/j.lwt.2011.10.001

Rozainee, M., Ngo, S.P., Salema, A.A. and Tan, K.G., Fluidized Bed Combustion of Rice Husk to Produce Amorphous Siliceous Ash, Energy Sustain. Dev., 12(1), 33-42 (2008). https://doi.org/10.1016/ S0973-0826(08)60417-2

Sardeing, R., Aubin, J. and Xuereb, C., Gas-Liquid Mass Transfer: A Comparison of Down and Up Pumping Axial Flow Impellers with Radial Turbines, Trans IChemE, 82(A12), 1589-1596 (2004). https://doi. org/10.1205/cerd.82.12.1589.58030

Schlomach, J. and Kind, M., Investigations on the Semi-Batch Precipitation of Silica, J. Colloid Interf. Sci., 277(2), 316-326 (2004). https://doi. org/10.1016/j.jcis.2004.04.051

Shim, J., Velmurugan, P., and Ohb, B.T., Extraction and Physical Characterization of Amorphous Silica Made from Corn Cob Ash at Variable $\mathrm{pH}$
Conditions Via Sol Gel Processing, J. Ind. Chem. Eng., 30, 249-253 (2015). https://doi.org/10.1016/j. jiec.2015.05.029

Sing, K.S.W., Everett, D.H., Haul, R.A.W., Moscou, L., Pierotti, R.A., Rouquerol, J., and Siemieniewska, T., Reporting Physisorption Data for Gas/Solid Systems with Special Reference to the Determination of Surface Area and Porosity, Pure \& App. Chem., 57(4), 603-619 (1985).

Srinivasan, V., Kullagounder, S., Srinivasan, S., and Thiraviyam, S., Synthesis of esoporous Silicon with Uniform Pore Size Using the Ashes of Husks from Panicum Miliare Millet: A Novel Recyclable Bio-Waste, Silicon, 2015, 1-7 (2015). https://doi. org/10.1007/s12633-015-9321-8

Subbukrishna, D.N., Suresh, K.C., Paul, P.J., Dasappa, S. and Rajan, N.K.S., Precipitated Silica from Rice Husk Ash by IPSIT Process. 15th European Biomass Conference \& Exhibition. Berlin (2007).

Tay, J.H. and Show, K.Y., Use of Ash Derived from OilPalm Waste Incineration as A Cement Replacement Material. Resources, Conservation and Recycling, 13(1), 27-36 (1995). https://doi.org/10.1016/09213449(94)00012-T

Utama, P.S., Yamsaengsung, R. and Sangwichien, C., Precipitated Silica Derived From Palm Oil Mill Fly Ash: Kinetics And Characterization, Key Eng. Mater., 673, 183-192 (2016). https://doi. org/10.4028/www.scientific.net/KEM.673.183

Zemnukhova, L.A., Egorov, A.G., Fedorishcheva, G.A., Barinov, N.N., Sokol'nitskaya, T.A. and Botsul, A.I., Properties of Amorphous Silica Produced from Rice and Oat Processing Waste, Inorg. Mater., 42(1), 24-29 ( 2006). https://doi. org/10.1134/S0020168506010067 